\title{
Key Concepts and Considerations Underpinning the Idea of Symbiotic Housing
}

\author{
Ar. Anamika Nandan \\ B.Arch., B.C.E. Patna, Ph.D. (Submitted), B.I.T. Mesra, Ranchi Asst. Professor, B.I.T. Patna
}

\section{Introduction}

The concept of symbiotic housing is very relevant in today's context. Symbiotic housing is a part of sustainable design. Efforts towards saving our environment, our earth and our lives have been made in different parts of the world in different ways.

"SYMBIOTIC" has been evolved from the word "SYMBIOSIS. It means the state of life of two living things which depend on each other for certain advantages. Symbiotic Housing is a type of housing where man and environment are symbiotic and urges the environmental policies to enable the urban system to replicate as closely as possible nature's inherently autonomous, stable and cyclical ecological system.

The concept of Symbiotic Housing demonstrates the value of smaller independent systems of water and energy supply and the value of living together in a close neighbourhood. The application of the simple and basic principles may help to bring back a greater social and ecological balance to urban housing. It offers several possibilities of avoiding / minimizing environmental impacts during construction \& future use.

Different approaches by the architects have emerged in the form of green architecture, solar architecture, sustainable designs, eco friendly designs, material based designs etc. Some architects are trying to produce designs in which local materials are being used so that energy consumed in the transportation of the material can be saved and at the same time cost can be reduced and also local people can get employment opportunities. Some architects are trying to use the benefits of solar system in their designs. Designs are analysed for their environmental impact and sustainability. Proper organization of available concepts, techniques, design elements and its output becomes very important for any kind of design.

It is important to search for a wide variety of approaches, technologies and organizational systems that help and address problems in housing and community development.

\section{The Concept And Its Uses In Various Parts Of The World}

The concept is being used in various parts of the world in recent years. Symbiotic housing is a concept which was initially used in Japan. In Japan housing is always one of the most important issues of all. In 1990, a group of professionals and firms from public and private sector joined forces, first functioning as a research body then as an organization for the promotion and realization of Symbiotic Housing from north to south in Japan. Uses of roof top for gardening, uses of windmill for generating common electricity, use of solar energy collector, uses of permeable surfaces for streets and parking areas are a few of the measures which were incorporated in a new housing project. Application of simple and basic principles, smaller independent systems of energy and water supply in housing colonies are some of the important features in the first symbiotic housing complex which is Setagaya-ku Fukasawa Symbiotic Housing Complex. Not only in Japan, but elsewhere also, the concept of symbiotic housing is becoming popular in many countries.

The need of symbiotic housing was felt because of the following reasons:-

- To create housing and living of higher quality lifestyle.

- To meet the need of the current generation without compromising the needs of future generation.

- To create a healthy, comfortable and safe environment.

- For the protection of ecosystem by minimizing the impact of building constructions.

- To maintain the stable ecosystems of diverse inhabitants in the middle of urban environment.

- For the effective use of natural energy

- For the cyclic use of energy, resources and waste materials

- For the implementation of restrictions in the use of energy and resources.

\section{Fundamentals Of Symbiotic Housing}

The following themes are important for establishing the theory of Symbiotic housing :

i. $\quad$ Energy Saving

ii. More effective use of natural resources 
iii. Compatibility and harmony with the local environment

iv. Health and Amenity

Its aim is the same all over the world while the approaches are different. The methods, concepts, use of materials, techniques may vary in the different parts of the world. It all depends on the living style of the people, their occupation, their habits etc. Symbiotic parameters are an up gradation of conventional parameters to sustainable parameters.
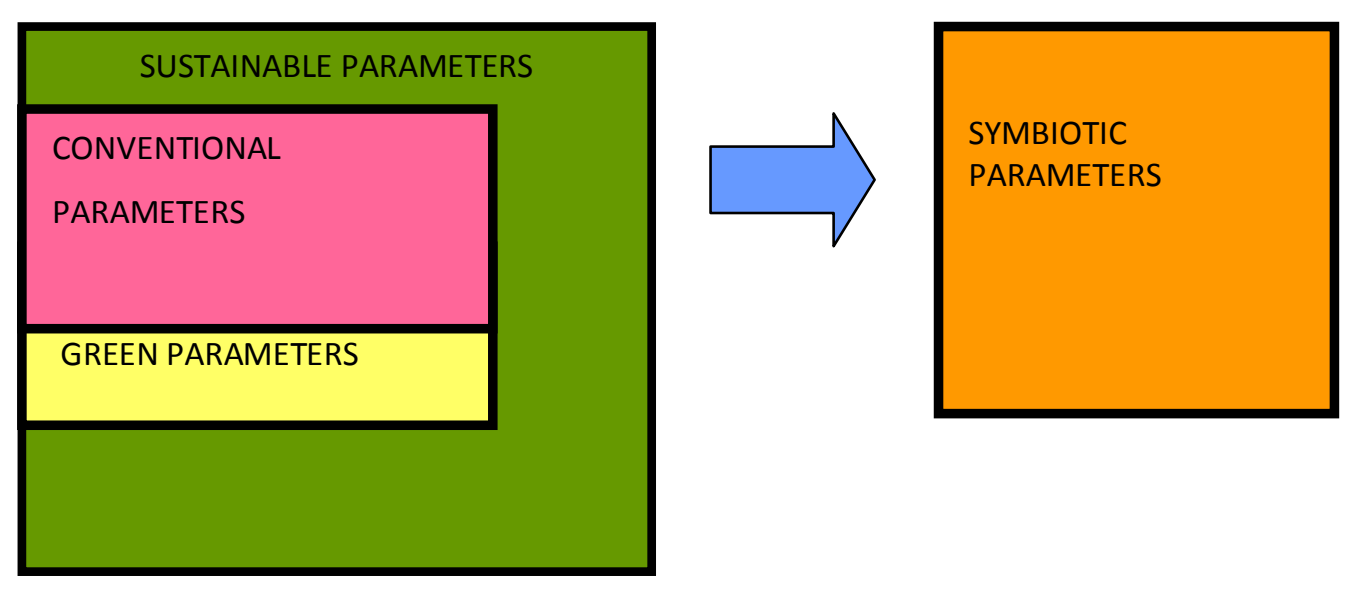
parameters.

Figure 2: Diagram showing the relationship among conventional, Green, sustainable and symbiotic

A good housing is always desirable. Good housing does not mean only structurally stable buildings. It is very important to provide an arrangement which is conducive for the health of the society and also for the environment of the locality. Certain variables such as building functionality( access, space, uses), open area in the plot, ventilation facilities, radiation, natural lighting inside the building., waste disposal etc. are very important and deciding factors for the quality of life of people living in them. Some of the fundamental issues related with $\mathrm{SH}$ are as follows:-

- Optimization of the use of Interior space -This can be done through careful design so that the overall building size and resource use in constructing and operating it are kept to a minimum.

- Use of high level of insulation -Performance winders and tight construction.

- Passive solar heating, day lighting and natural cooling can be incorporated cost effectively into most buildings. Also consider solar water heating and photo voltaic panels or design buildings for the future solar installations. Active solar architecture may also be incorporated.

- Minimize waste by designing for standard ceiling heights and building dimensions Avoid waste from structural over- design (use optimum, value engineering / advanced framing) and keeping building geometry simple.

- Design landscape to absorb rainwater runoff (storm water) rather than having to carry it off site in storm sewers. In arid areas, roof top water catchments systems should be considered for collecting rainwater and using it for landscape irrigation.

\section{Conclusion}

The present scenario and the emerging scenario of environmental conditions demand a radical shift in planning and design paradigm. Rising urbanization, increasing population, increasing pollution and decreasing environmental conditions lead to a process of design which is a new language of architecture.

\section{References:}

[1]. Www.inive.org. IWAMURA,K. (May 2005). "Passive and Low Energy Cooling for the Built Environment"-paper presented in an International Conference at Santorini, Greece, viewed 12/6/2007.

[2]. CHATTOPADHYAY, S. (September-October 2004). Spatio - Economic Development Record, Vol.11, No. 5, pp. 17-21.

[3]. KUNDOO, ANUPAMA. (2004).Sustainable Buildings, Design Manual, volume - 2, published by The Energy and Resource Institute, New Delhi, p.- 4.

[4]. BAYO, AKINBAMJO OLUMUYIWA. "Sustainable Development And Gender Relation: The Housing Dimension", Ondo State Nigeria.

[5]. DATAR, RAHUL. (July 2001). “Towards Sustainable Construction”, Journal of Indian Institute of Architects, PP. 21-24.

[6]. Journal of Housing Research Foundation, 2006, No.32.

[7]. Www.patna.nic.in. viewed 17.09.2007. 